\title{
DESAFIOS E OBSTÁCULOS PARA A CONSOLIDAÇÃO DE UM ECOSSISTEMA DE EMPREENDEDORISMO NA CIDADE DO RIO DE JANEIRO: UMA ANÁLISE COM BASE NA VISÃO DOS PRINCIPAIS PLAYERS
}

CHALLENGES AND CONSTRAINTS TO THE STRENGTHENING OF AN ENTREPRENEURIAL ECOSYSTEM IN THE CITY OF RIO DE JANEIRO: AN ANALYSIS BASED ON THE MAIN PLAYERS' VIEW

\section{Guilherme de Oliveira Santos}

Doutorando no Programa de Pós Graduação em Políticas Públicas, Estratégias e Desenvolvimento (PPED) do Instituto de Economia da Universidade Federal do Rio de Janeiro (IE/UFRJ)

Data de recebimento: 15/02/2018 Data de aceite: 25/06/2018

\section{Fabio Vieira Pereira Cendão Peixoto}

Pós-graduado em Direito Privado pela Universidade Cândido Mendes (UCAM), LL. M. em

Direito Corporativo pelo Instituto Brasileiro de Mercado de Capitais (IBMEC)

\section{RESUMO}

Este artigo tem como objetivo investigar os desafios e obstáculos para a consolidação de um Ecossistema de Empreendedorismo no Rio de Janeiro. Para tanto, em primeiro lugar foi feita uma revisão bibliográfica sobre Ecossistemas de Empreendedorismo, bem como uma contextualização do cenário atual com base em dados secundários. Em seguida, foram realizadas entrevistas - por e-mail - com diferentes atores que compõem o Ecossistema de Empreendedorismo do Rio de Janeiro. As respostas foram analisadas por meio da técnica de Análise de Conteúdo, a partir das categorias definidas. Os resultados apontam que o Ecossistema de Empreendedorismo do Rio de Janeiro ainda é pouco desenvolvido, apesar de ter grande potencial de crescimento. Os principais obstáculos e desafios identificados são: o excesso de burocracia; a reduzida disponibilidade de capital; a falta de articulação entre os atores; a realização periódica de eventos para empreendedores e a criação de espaços compartilhados; e um maior estímulo a investimentos de impacto.

Palavras-chave: Ecossistema. Startups. Empreendedorismo. Rio de Janeiro. Inovação.

\section{ABSTRACT}

The purpose of this article is studying the challenges and constraints to the strengthening of an Entrepreneurial Ecosystem in the city of Rio de Janeiro. For this purpose, firstly we did a bibliographic review about entrepreneurial ecosystems and a contextualization of the current scenario based on secondary data. Afterwards, we carried out interviews by e-mail with different actors that compose the entrepreneurial ecosystem of Rio de Janeiro. The answers were analyzed through the Content Analysis technique, based on the selected categories. The results indicate that the entrepreneurial ecosystem of Rio de Janeiro is still shortly developed, in spite of its great growth potential. The main obstacles and challenges are: the excessive bureaucracy; the limited availability of funding; the lack of articulation among the actors; the increase of the number of events for entrepreneurs and the creation of shared spaces; and a bigger incentive to impact investing.

Keywords: Ecosystem. Startups. Entrepreneurship. City of Rio de Janeiro. Innovation. 


\section{INTRODUÇÃO}

Atualmente, os Ecossistemas de Empreendedorismo têm sido alvo de interesse crescente em diversos países (KANTIS; FEDERICO, 2012), na medida em que são cada vez mais reconhecidos como alavancas de inovação, progresso tecnológico e desenvolvimento econômico (ACS; DESAl; HESSELS, 2008). Tais ecossistemas se caracterizam pela combinação de elementos culturais, econômicos, políticos e sociais dentro de uma região que apoiam o desenvolvimento e crescimento de startups inovadoras (MASON; BROWN, 2014; STAM, 2015; ROUNDY, 2016). Para serem bem-sucedidos, os Ecossistemas devem possuir os seguintes atributos: cultura propícia, políticas públicas de apoio, disponibilidade de financiamento apropriado, qualidade do capital humano, mercados abertos, e um conjunto de instituições de suporte. Entretanto, não basta que estas dimensões existam isoladamente, é imperioso que elas interajam de maneira autônoma, orgânica e complexa (ISENBERG, 2010; FELD, 2012).

Apesar de ser a segunda cidade mais importante do País, o Rio de Janeiro ocupa somente a $14^{\circ}$ posição no Índice de Cidades Empreendedoras (ICE) feito pela Endeavor Brasil (2016), apresentando uma trajetória de queda em relação aos anos de 2015, quando ficou na $10^{\circ}$ posição, e 2014, quando ocupava a 9a posição. Outra pesquisa realizada pela mesma instituição mostrou que a cidade possui pontos fortes como: qualidade e estilo de vida; capital humano qualificado; e grande mercado consumidor. Não obstante, ainda enfrenta desafios, dentre os quais: falta de cultura empreendedora; alto nível de desigualdade; e excesso de burocracia. Desta maneira, este artigo tem como objetivo responder a seguinte pergunta: Quais são os desafios e obstáculos para a consolidação de um Ecossistema de Empreendedorismo na cidade do Rio de Janeiro?

Para tanto, em primeiro lugar foi feita uma revisão bibliográfica sobre Ecossistemas de Empreendedorismo, bem como uma contextualização do cenário atual com base em dados secundários. Em seguida, foram realizadas entrevistas - por e-mail - com diferentes atores que compõem o Ecossistema de Empreendedorismo do Rio de Janeiro, dentre os quais: empreendedores, investidores, capitalistas de risco, representantes do setor público, acadêmicos, e representantes de instituições de suporte, tais como incubadoras, aceleradoras e associações. Estas entrevistas tiveram como objetivo analisar a percepção destes atores no que se refere às seguintes dimensões: políticas públicas, acesso a capital, cultura empreendedora, papel das universidades e instituições de suporte, articulação dos atores que compõem o ecossistema, e dificuldades enfrentadas pelas startups. As respostas foram organizadas e analisadas por meio da técnica de Análise de Conteúdo, a partir das categorias definidas.

Os resultados apontam que o Ecossistema de Empreendedorismo do Rio de Janeiro ainda é pouco desenvolvido, apesar de ter grande potencial de crescimento. Os principais obstáculos apontados são: a falta de uma cultura empreendedora; o excesso de burocracia; a reduzida disponibilidade de capital; e a falta de articulação entre os atores. Os principais desafios são: o engajamento e articulação entre atores; a melhoria do ambiente de negócios; a realização periódica de eventos para empreendedores e a criação de espaços compartilhados; o desenvolvimento de uma cultura em- 
preendedora mais cooperativa; o alinhamento das políticas públicas de apoio ao empreendedorismo; e maior estímulo a investimentos de impacto.

\section{REFERENCIAL TEÓRICO: ECOSSISTEMAS DE EMPREENDEDORISMO}

\subsection{DEFINIÇÃO DO CONCEITO}

Os Ecossistemas de Empreendedorismo têm sido alvo de interesse crescente em diversos países (e.g., KANTIS; FEDERICO, 2012), na medida em que são cada vez mais reconhecidos como alavancas de inovação, progresso tecnológico e desenvolvimento econômico, que, por seu turno, estão diretamente associados à criação de empregos, crescimento de salários e revitalização urbana (ACS; DESAI; HESSELS, 2008). Entretanto, apesar do recente aumento de sua popularidade, sobretudo em virtude do impacto dos trabalhos de Feld (2012) e Isenberg (2010), não existe ainda uma definição de Ecossistema de Empreendedorismo (EE) que seja amplamente compartilhada entre pesquisadores ou profissionais.

Roundy (2016) define um Ecossistema de Empreendedorismo como um "conjunto de atores, instituições, estruturas sociais e valores culturais que produzem atividade empreendedora". De maneira similar, Isenberg (2010) descreve um EE como um "conjunto de elementos individuais - tais como liderança, cultura, mercado de capitais, e consumidores com mente aberta - que se combinam de maneiras complexas".

Stam (2015), por seu turno, argumenta que um Ecossistema de Empreendedorismo é resultado “(d)as combinações de elementos culturais, econô- micos, políticos e sociais dentro de uma região que apoiam o desenvolvimento e crescimento de startups inovadoras e encorajam os empreendedores nascentes e outros atores a tomarem riscos para começar, financiar e de alguma forma apoiar negócios de alto risco". Com base nas diversas contribuições encontradas na literatura, Mason e Brown (2014) sintetizam a definição de um Ecossistema Empreendedor da seguinte forma:

Um conjunto interconectado de atores empreendedores (tanto potenciais quanto existentes), organizações empreendedoras (e.g. firmas, capitalistas de risco, investidores anjo, bancos), instituições (universidades, agências do setor público, instituições financeiras), e processos empreendedores (e.g. taxa de nascimento de negócios, número de firmas de alto crescimento, níveis de empreendedorismo de alto impacto, número de empreendedores seriais, níveis de ambição empreendedora), que de maneira formal e informal criam uma amálgama capaz de conectar, mediar, e governar a performance dentro de um ambiente empreendedor local. (MASON; BROWN, 2014, p. 5).

As diferentes definições apresentadas confirmam a percepção de Roundy (2016), em relação ao fato de que as pesquisas recentes sobre EE focam cada vez mais nas estruturas sociais e nas conexões entre os participantes dos ecossistemas, em detrimento de analisar suas dimensões de forma isolada.

\subsection{ATRIBUTOS DE SUCESSO DE UM ECOSSISTEMA DE EMPREENDEDORISMO}

Em sua obra Startup Communities, Feld (2012) elenca nove atributos para uma comuni- 
dade de startups ser bem-sucedida, incluindo liderança, presença de intermediários, densidade das redes, apoio do governo, oferta de trabalhadores qualificados, diversidade de serviços de apoio, alto nível de engajamento, grandes empresas que sirvam como âncoras, e grande disponibilidade de capital, sobretudo de risco.

Considerando o papel do Estado na promoção de Ecossistemas de Empreendedorismo, Isenberg (2010) aponta que os gestores públicos devem enfatizar o papel das condições locais e de processos bottom-up; enfatizar o empreendedorismo ambicioso, ou seja, favorecer os empreendedores de alto impacto; e focar nas instituições, sobretudo no estímulo ao desenvolvimento de uma cultura empreendedora e no estabelecimento de um framework legal, burocrático e regulatório propício ao desenvolvimento do empreendedorismo.
Na mesma linha, Fuerlinger et al. (2015), ao analisar o caso da Alemanha, destacam a necessidade de: i) alinhamento dos incentivos aos profissionais científicos às atividades de transferência tecnológica; ii) ampliação do financiamento para as fases seguintes à criação de empresas, envolvendo financiadores privados; iii) implementação de políticas que visem a mudança dos valores sociais e atitudes em relação ao empreendedorismo com objetivo de reduzir o estigma do fracasso e melhorar a percepção da atividade empreendedora na sociedade.

Com objetivo de sistematiza o conceito, Isenberg (2011) identificou seis domínios distintos dentro de um Ecossistema de Empreendedorismo: uma cultura propícia, políticas públicas de apoio, disponibilidade de financiamento apropriada, qualidade do capital humano, mercados abertos, e um conjunto de instituições de suporte (ver Figura 1). 
Figura 1 - Domínios de um Ecossistema de Empreendedorismo e seus Componentes

BABSON

GLOBAL

Clientes iniciais
- Early adopters para provar o

- Early adopters para provar o

conceito

Pericia em por em marcha

(produzir)

- Cliente referência

- Primeiros comentários

- Canais de distribuição

Redes

- Redes de empreendedores

- Redes diáspora

- Corporações multinacionais

\section{Mão de obra}

- Treinada e não treinada

- Empreendedores seriais

- Famílias de gerações subsequentes

Instituições educacionais

- Diplomas gerais (profissionais e acadêmicos)

- Treinamento específico para o

empreendedorismo

\section{Infra-estrutura}

- Telecomunicações

- Transportes \& logística

- Energia

- Zonas industriais, centros de incubação,

clusters

\section{Domínios do Ecossistema Empreendedor}

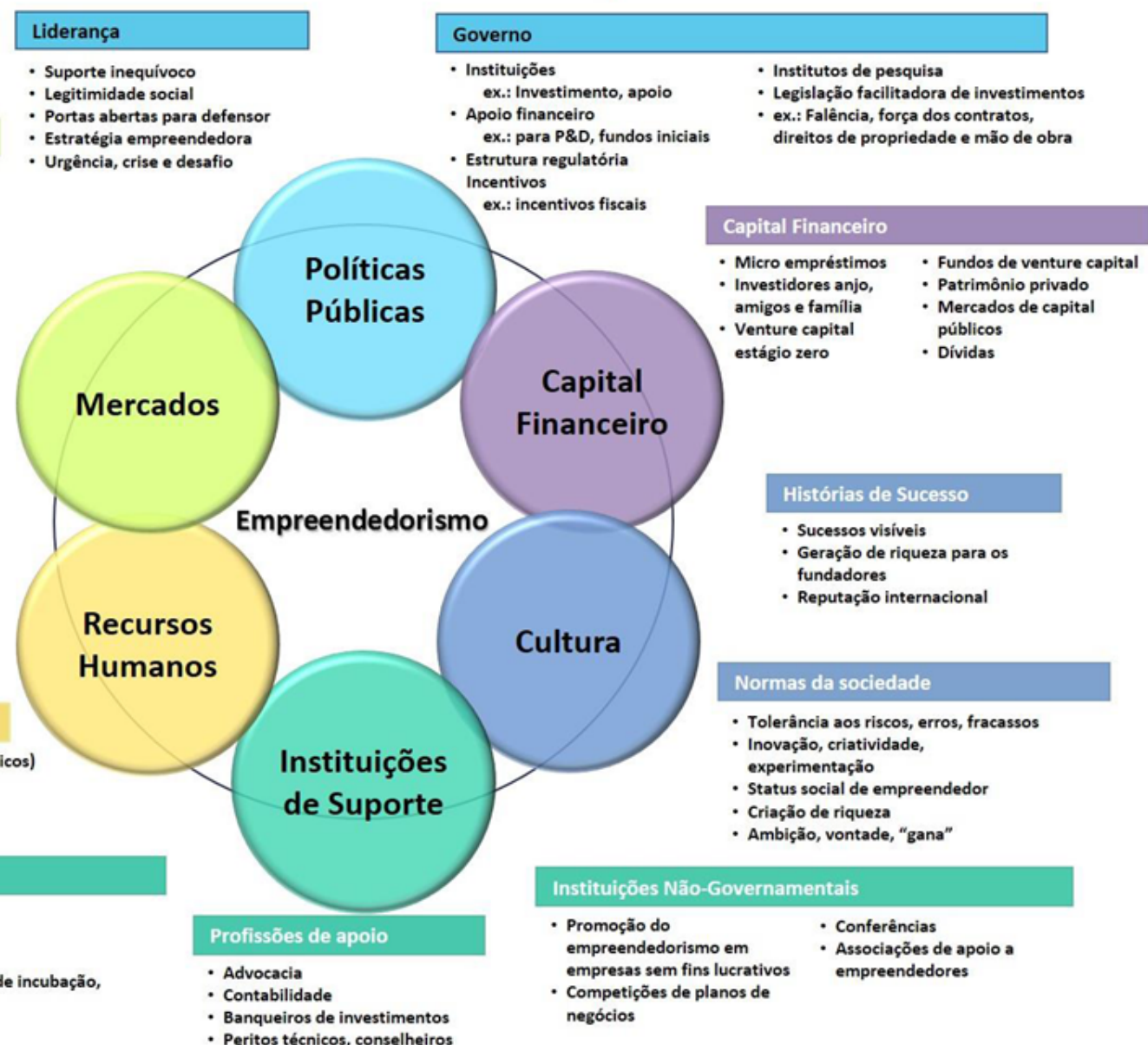

Fonte: Isenberg (2010) e Oliveira et al. (2013)

Stam e Spigel (2016), por seu turno, distinguem os elementos de um Ecossistema de Empreendedorismo em duas categorias: condições de framework e condições sistêmicas. As condições de framework incluem as condições sociais (instituições formais e informais) e as condições físicas que estimulam e restringem a interação humana; ao passo que as condições sistêmicas estão no coração do ecossistema: redes de empreendedores, liderança, financiamento, talentos, conhecimento e serviços de apoio. A presença destes elementos e a interação entre eles são cruciais para o sucesso do ecossistema.
Segundo Stam (2015), um Ecossistema de Empreendedorismo é caracterizado por uma causalidade multidirecional e uma alta interatividade. Por exemplo, exemplos de crescimento do empreendedorismo em uma região são um output do ecossistema, mas eles também são parte uma dinâmica de feedback que inspiram outros empreendedores a terem sucesso. Adicionalmente, negócios bem-sucedidos podem interagir com redes pessoais ou normas sociais que valorizam o sucesso financeiro para acelerar essa dinâmica de feedback. Deste modo, não basta que a região possua os atributos do ecossistema individual- 
mente, é preciso que eles interajam de maneira autônoma, orgânica e complexa (Isenberg, 2015).

O sucesso de um Ecossistema de Empreendedorismo, portanto, passa pela geração de um ciclo virtuoso, resultante da construção de empreendimentos de sucesso que servem como modelos a seguir, e, posteriormente, contribuem para atrair para a região empreendedores interessados em imitar estes modelos (Carvalho et al., 2016). Por outro lado, Ecossistemas de Empreendedorismo podem ficar presos em ciclos viciosos, caracterizados por uma cultura desfavorável à empresa, pouco acesso a capital de risco e baixa taxa de empreendedorismo (Venkataraman, 2004).

No nível micro, Gomes (2013) investigou o papel dos empreendedores e das incertezas nos Ecossistemas de Empreendedorismo, aspectos pouco investigados na literatura. O autor sugere que se devidamente gerenciadas, as incertezas podem ser uma fonte de valor e vantagem competitiva para as empresas inovadoras e para os ecossistemas como um todo. Os empreendedores, por sua vez, possuem papel central neste processo ao "conectar incertezas" e "mitigar e amplificar" os efeitos de propagação de incertezas.

Por fim, observa-se que os Ecossistemas de Empreendedorismo geralmente emergem em lugares que possuem ativos específicos, ou interdependências não comercializáveis na definição de Storper (1997). Não obstante, como apontam Kantis e Federico (2012), no caso específico da América Latina, existem diversos fatores sociais, culturais e econômicos que possuem uma influência negativa no contexto empreendedor na comparação com outras regiões. De fato, há evidência suficiente mostrando que o número de negócios inovadores e orientados para o crescimento nesta região é limitado. Com efeito, a maioria dos novos negócios criados tende a ser de microempresas com baixa expectativa de crescimento e, por isso, com pouco impacto no nível macro (Kelly et al., 2010).

\section{CONTEXTO RECENTE DO ECOSSISTEMA DE EMPREENDEDORISMO DO RIO DE JANEIRO}

De acordo com o Índice de Cidades Empreendedoras, desenvolvido pela Endeavor Brasil, o Rio de Janeiro ocupava a $9^{a}$ posição em 2014, a $10^{\text {a }}$ posição em 2015, e em 2016, o RJ perdeu quatro posições, ocupando somente a $14^{a}$ posição. Neste último levantamento, o Rio ficou atrás de cidades menores e menos importantes economicamente como Joinville, Vitória, Sorocaba, Maringá, Caxias do Sul e Blumenau.

Para a construção do Índice, a Endeavor Brasil elaborou um framework adequado à realidade do país, com base nas ferramentas utilizadas internacionalmente. Este framework está estruturado a partir de sete pilares: Ambiente Regulatório, Infraestrutura, Mercado, Acesso a Capital, Inovação, Capital Humano e Cultura Empreendedora.

No que diz respeito ao Ambiente Regulatório, a cidade do Rio teve o seu pior desempenho, ficando na última posição $\left(32^{\circ}\right)$ dentre todas as cidades selecionadas. Esta performance ruim explica-se pelo longo tempo para abrir empresas e regularizar imóveis na cidade; pelo alto custo dos impostos, sobretudo ICMS e IPTU; e pela enorme complexidade tributária, que deriva do grande número de atualizações realizadas. Na dimensão "Infraestrutura", a capital fluminense ocupa a $16^{a}$ posição. Seu 
desempenho é demasiadamente prejudicado pelas condições urbanas, com destaque para o alto preço do $\mathrm{m}^{2}$ e custo médio da energia elétrica.

No que se refere ao Mercado, o RJ registra um bom desempenho, ocupando a sexta posição. Esta performance é auxiliada pelo tamanho do PIB - segundo maior do país -; pelo alto índice de empresas exportadoras sediadas na cidade; e pelo potencial de clientes, resultante da sua elevada renda per capita. No quesito "Acesso a Capital" o RJ ocupa a $5^{\text {a }}$ posição, o que decorre, sobretudo, da disponibilidade relativamente ampla de capital de risco na cidade. No tocante à Inovação, o Rio registra seu melhor desempenho, ficando na $3^{a}$ posição. Esta performance está fortemente relacionada com os inputs para a inovação, tais como proporção de mestres e doutores, percentual de funcionários na área de C\&T e infraestrutura tecnológica.

Em relação ao Capital Humano, a cidade do Rio possui desempenho razoável (10 lugar). Nesta dimensão o destaque fica por conta da mão de obra qualificada, especialmente no que diz respeito ao percentual de trabalhadores com Ensino Superior. Finalmente, no que concerne à cultura empreendedora, a cidade do Rio de Janeiro ocupa somente a $17^{a}$ posição, tendo desempenho mediano nos índices de potencial para empreender com alto impacto e de imagem do empreendedorismo.

Em outro estudo, intitulado "Rio de Janeiro Empreendedor", a Endeavor Brasil identificou os pontos fortes e os desafios que a Cidade Maravilhosa possui para se tornar a capital do empreendedorismo. A pesquisa mostrou que o Rio de Janeiro, dentre as capitais, possui uma das piores taxas de atividade entre pessoas de 24 a 49 anos, ou seja, pessoas em idade para trabalhar e que não estão trabalhando. Observou-se também que entre as capitais do Sudeste, o RJ possui a menor taxa de sobrevivência de empresas com dois anos de abertura. Além disso, a proporção de empresas de alto crescimento no Rio de Janeiro, em relação às empresas com pelo menos 10 funcionários, ainda é uma das mais baixas do Brasil, igual a 6,3\%.

Com relação aos pontos fortes, o estudo destaca em primeiro lugar a qualidade de vida e o lifestyle carioca, enfatizando as belezas naturais e arquitetônicas, bem como a intensa vida cultural que a cidade possui. Outro diferencial da cidade apontado é o capital humano local e o apoio ao empreendedor. Nesta dimensão, destacam-se: a escolaridade da mão de obra; a concentração de Universidades de ponta, de Institutos de Pesquisa e de Centros de P\&D públicos e privados; a presença de incubadoras de empresas e parques tecnológicos relevantes; a disponibilidade relativamente alta de capital de risco; e a existência de um programa governamental de apoio aos empreendedores, o Startup Rio. Finalmente, a pesquisa destaca como potencial o grande mercado consumidor local que o RJ possui, em decorrência da renda elevada e dos recentes investimentos em infraestrutura.

Por outro lado, a pesquisa salienta que a capital fluminense ainda enfrenta alguns desafios importantes. Em primeiro lugar encontra-se a falta de uma cultura empreendedora de alto impacto, devido ao baixo desejo de empreender entre funcionários e da falta de orientação adequada para superar os desafios relativos à 
atividade empreendedora. Em segundo lugar, o estudo destaca a grande desigualdade socioeconômica da cidade, que reflete em uma desigualdade no empreendedorismo, entre aqueles que possuem condições iniciais favoráveis - escolaridade e renda - e os que acabam sendo impelidos a permanecerem na informalidade. Por último, a pesquisa reforça a questão do excesso de burocracia como um dos principais obstáculos para o desenvolvimento do empreendedorismo de alto impacto na capital fluminense.

\section{METODOLOGIA}

Em primeiro lugar foi feita uma revisão bibliográfica sobre Ecossistemas de Empreendedorismo com base em artigos científicos, livros, estudos e relatórios. Esta revisão auxiliou na definição do conceito de Ecossistema de Empreendedorismo, bem como na identificação dos principais domínios e atributos do mesmo. Em seguida, buscamos retratar o contexto recente do Ecossistema de Empreendedorismo da cidade do
Rio de Janeiro com base em pesquisas anteriores e no levantamento de dados secundários.

A partir do referencial teórico e da contextualização do ecossistema, montamos um questionário e selecionamos players do ecossistema relevantes em diferentes áreas, incluindo: empreendedores, investidores, capitalistas de risco, representantes do setor público, acadêmicos, e representantes de instituições de suporte, tais como incubadoras, aceleradoras e associações (ver Quadro 1). As entrevistas - feitas por e-mail - tiveram como objetivo analisar a percepção destes atores no que se refere às seguintes dimensões: políticas públicas; acesso a capital; cultura empreendedora; papel das universidades e instituições de suporte; articulação dos atores que compõem o ecossistema; e dificuldades enfrentadas pelas startups. As entrevistas foram realizadas por e-mail tendo como objetivo a coleta de respostas mais focadas nas perguntas, com maior tempo para elaboração das respostas pelos entrevistados, bem como maior confiança no conteúdo final registrado, sem qualquer interferência de fatores não objetivos da entrevista (Meho, 2006).

Quadro 1 - Entrevistados e Identificação no artigo

\begin{tabular}{|c|c|}
\hline Entrevistados & Identificação no Artigo \\
\hline Representante de Universidade - PUC-Rio & (Entrevistado 1, 2017) \\
\hline Representante de Instituição de Suporte - Instituto IBMEC & (Entrevistado 2, 2017) \\
\hline Representante de Universidade - UFRJ & (Entrevistado 3, 2017) \\
\hline Empreendedor - Nibo & (Entrevistado 4, 2017) \\
\hline Empreendedor - Finxi & (Entrevistado 5, 2017) \\
\hline Investidor & (Entrevistado 6, 2017) \\
\hline Representante de Grupo Associativo de Capital de Risco - Gávea Angels & (Entrevistada 7, 2017) \\
\hline Representante de Aceleradora - Shell Iniciativa Jovem & (Entrevistado 8, 2017) \\
\hline Representante de Aceleradora - ACE & (Entrevistado 9, 2017) \\
\hline Representante de Incubadora - Instituto Gênesis & (Entrevistado 10, 2017) \\
\hline Representante de Associação - ACRio & (Entrevistado 11, 2017) \\
\hline
\end{tabular}




\begin{tabular}{|l|c|}
\hline Representante de Associação - ASSESPRO-RJ & (Entrevistada 12, 2017) \\
\hline $\begin{array}{l}\text { Representante de Instituição de Suporte - Serviços jurídicos para Startups } \\
\text { - Faria, Cendão \& Maia Advogados }\end{array}$ & (Entrevistado 13, 2017) \\
\hline Representantes de Instituição de Suporte - ITS & (Entrevistados 14, 2017) \\
\hline Representante de Coworking - Nex Rio & (Entrevistada 15, 2017) \\
\hline Representante da FIRJAN & (Entrevistada 16, 2017) \\
\hline Representante do Sebrae & (Entrevistado 17, 2017) \\
\hline Deputado Federal & (Entrevistado 18, 2017) \\
\hline Representante de Comunidade de Startups - Cariocas & (Entrevistado 19, 2017) \\
\hline Representante de Plataforma voltada para Empreendedores - StartSe & (Entrevistado 20, 2017) \\
\hline
\end{tabular}

Fonte: Elaboração Própria (2017)

Após recebidas, as entrevistas foram analisadas por meio da técnica de Análise de Conteúdo, seguindo as etapas propostas por Bardin (2011). Estas etapas se organizam em três fases: 1) pré-análise, 2) exploração do material e 3) tratamento dos resultados, inferência e interpretação. Na primeira fase, pré-análise, o objetivo foi sistematizar as ideias iniciais colocadas pelo referencial teórico e estabelecer indicadores para a interpretação das informações coletadas. Concluída esta fase, passou-se para a exploração do material, que consiste na "construção das operações de codificação, considerando-se os recortes dos textos em unidades de registros, a definição de regras de contagem e a classificação e agregação das informações em categorias simbólicas ou temáticas" (Silva e Fossá, 2013).

Desse modo, o texto das entrevistas foi recortado em unidades de registro (palavras, frases, parágrafos), agrupadas tematicamente em categorias e subcategorias, as quais possibilitaram as inferências. De tais trechos foram identificadas palavras-chave relativas às categorias de análise definidas como mostra o Quadro 2:

Quadro 2 - Categoria de Análise e Palavras-Chave

\begin{tabular}{|c|c|c|c|}
\hline Categorias & \multicolumn{3}{|c|}{ Palavras-Chave } \\
\hline Desafios & Ecossistema & Startups & Densidade \\
\hline \multirow{2}{*}{ Obstáculos } & Burocracia & & Infraestrutura \\
\hline & Custos & & Legislação \\
\hline \multirow{2}{*}{ Articulação } & Redes & & Interação \\
\hline & Comunidades & & Relacionamento \\
\hline Capital Financeiro & Investidores & & Capital de Risco \\
\hline Cultura & Risco & & Fracasso \\
\hline \multirow{2}{*}{$\begin{array}{l}\text { Instituições de } \\
\text { Suporte }\end{array}$} & Incubadoras & & Associações \\
\hline & Aceleradoras & & Universidades \\
\hline Políticas Públicas & Investimento & & Apoio \\
\hline \multirow{2}{*}{ Propostas } & Eventos & & Planejamento \\
\hline & Espaços & & Integração \\
\hline
\end{tabular}

Fonte: Elaboração própria (2017) 
Por fim, a terceira fase compreendeu o tratamento dos resultados, inferência e interpretação, buscando captar os conteúdos manifestos e latentes contidos em todo material coletado (Silva e Fossá, 2013).

\section{RESULTADOS}

\subsection{DESAFIOS}

De forma geral, os entrevistados concordam que o Ecossistema de Empreendedorismo da cidade do Rio de Janeiro está nos estágios iniciais de desenvolvimento, aquém de ecossistemas de outras cidades brasileiras, como São Paulo, Belo Horizonte e Florianópolis, e mais distante ainda dos principais ecossistemas do mundo.

Alguns entrevistados possuem uma visão bastante crítica do ecossistema carioca, qualificando-o como "rudimentar" (Entrevistado 1, 2017); "iniciante e pouco produtivo" (Entrevistado 2, 2017); "imaturo" (Entrevistado 8, 2017); e "muito fraco, passando de inexistente para embrionário" (Entrevistado 4, 2017). Segundo o entrevistado que atua como investidor, o ecossistema "evolui de forma lenta, abaixo do que gostaríamos" (Entrevistado 6, 2017).

Nesta linha, o representante de uma comunidade de startups da cidade enfatiza que:

[...] no Rio de Janeiro não temos um ecossistema estruturado. Sofremos com crises de ego e disputas entre membros de grupos ou subgrupos que não sabem colaborar. $O$ primeiro indício de um ecossistema em crise é a falta de colaboração. (Entrevistado 19, 2017, grifo nosso).
E o representante de uma aceleradora de startups completa:

Por conta dessa imaturidade os investidores são mais receosos, e os demais players como aceleradoras, parques tecnológicos, incubadoras e instituições de fomento não conseguem se desenvolver. O governo/prefeitura não tem um papel definido e atuante, o que enfraquece ainda mais. (Entrevistado 8, 2017).

Outro desafio percebido por grande parte dos entrevistados é o fato do ecossistema carioca ser pouco denso e muito concentrado em algumas partes específicas da cidade, resultando na formação de "ilhas" com dificuldade de se integrar.

Você tem ilhas. A PUC, por exemplo, é uma ilha [...]. [Mas] se você comparar com a massa, é uma exceção. (Entrevistado 1, 2017).

Acho que falta densidade, o fato das startups estarem espalhadas pela cidade não ajuda. (Entrevistado 4, 2017, grifo nosso).

Acho que o ecossistema do Rio é uma rede muito polarizada e pouco distribuída, o capital financeiro e de influência estão muito concentrados em alguns nichos e regiões, então nem sempre o ecossistema é aberto e acessível pra quem está fora desses eixos. (Entrevistado 11, 2017, grifo nosso). Nossa percepção é de que o ecossistema carioca é uma bolha, bem densa, localizada principalmente no Centro do Rio. (Entrevistada 15, 2017, grifo nosso).

Apesar das visões críticas e dos problemas apontados, há uma percepção por parte dos entre- 
vistados de que o ecossistema carioca possui qualidades e potencial de crescimento, mas esbarra em alguns desafios como: falta de articulação e mobilização, carência de organização institucional, dificuldades de gestão, e desafios de retenção de talentos.

[...] as pessoas boas estão sendo puxadas pra fora do ecossistema. Então, tem um desafio de retenção. (Entrevistado 1, 2017, grifo nosso).

É o que tem o maior potencial, ambiente, universidades, clima, natureza, praia e proximidade geográfica. Porém, é o pior aproveitado por questões de gestão. (Entrevistado 10, 2017, grifo nosso).

O ecossistema de startups do Rio é bem desenvolvido e amplo, mas pouco conectado. Muitos fazem as mesmas ações, o que confunde as startups. (Entrevistado 17, 2017, grifo nosso).

O nosso ecossistema é fértil, há muitas iniciativas pululando por aí. No entanto, carecemos de mais organização institucional para agregar empreendedores, instituições acadêmicas, investidores, órgãos públicos. (Entrevistado 18, 2017, grifo nosso).

\subsection{OBSTÁCULOS}

Os obstáculos identificados pelos entrevistados se dividem em dois níveis. No nível macro situam-se os problemas nacionais que impactam a atividade empreendedora, tais como excesso de burocracia, questões legais - trabalhista, fiscal, tributária, regulatória -, e a crise econômica que o país atravessa.

[...] [Os obstáculos tem relação com] toda a parte burocrática, legal, as complicações legais para tocar um empreendimento; isto envolve questão fiscal, questão trabalhista, questão societária, e por aí vai. (Entrevistado 1, 2017, grifo nosso).

Entendo que isso é uma deficiência inerente a problemas macronacionais como: (...) elevada taxa de juros (...); legislação não específica ao setor (desde riscos trabalhistas a tributação não diferenciada); e dificuldades padrões de se empreender no Brasil (mercado, burocracia, riscos). (Entrevistado 6, 2017, grifo nosso).

No nível micro, os entrevistados ressaltam problemas específicos da cidade do Rio de Janeiro, como os altos custos - de aluguel, mão de obra, e de vida -, violência urbana, mobilidade urbana ineficiente, infraestrutura precária, dificuldade de acesso a capital e falta de conhecimento empreendedor por parte dos atores.

[...] os custos que existem para montar uma startup no Rio de Janeiro são altíssimos. [...] [O] aluguel [é] caro, falta espaço, falta capital de risco; pensa nos provedores de internet, são pouquíssimos, provedores de qualidade muito ruim. (Entrevistado 1, 2017, grifo nosso).

A cidade poderia oferecer uma boa qualidade de vida, mas a violência e os custos elevados estão minando esse benefício. (Entrevistado 4, 2017, grifo nosso).

\section{A mobilidade urbana ainda é um problema,} visto que perco 45 minutos para ir pra Barra [da Tijuca] de metrô, por exemplo. (Entrevistado 5, 2017, grifo nosso).

[Obstáculos:] acesso a capital humano, financeiro, estratégico. Planejamento e capabilities empreendedoras. Saber estruturar deals, saber 
negociar, saber captar investimento, saber conversar com pessoas. (Entrevistado 5, 2017).

\subsection{ARTICULAÇÃO}

No que se refere à articulação dos atores que compõem o ecossistema, os entrevistados sinalizam que há pouca interação devido a problemas como: dificuldade de comunicação e diálogo, desinteresse em cooperar, e falta de engajamento e mobilização. Dessa forma, acumulam-se iniciativas isoladas, que não se conectam e muitas vezes se sobrepõem, impactando negativamente a dinâmica do ecossistema.

[Existe] uma série de atores que mexem com empreendedorismo, que vão desde agências de fomento, universidades, grupos de capitalistas de risco, e coisas do tipo, mas eu não vejo muita articulação acontecendo. (Entrevistado 1, 2017, grifo nosso).

[...] o Rio de Janeiro tem pecado por ter inúmeras ilhas onde a comunicação é mínima entre elas e o interesse em cooperar quase inexistente, salvo raríssimas exceções. (Entrevistado 3, 2017, grifo nosso).

[...] falta engajamento das pessoas em buscarem construir uma rede [...]. (Entrevistado 9, 2017, grifo nosso).

\section{A articulação é ruim, porque todo mundo} quer fazer sozinho. Pegar tudo para si. Surgem iniciativas verticais e caras que não sobrevivem. Tanto privada, para-governamental ou governamental. (Entrevistado 10, 2017, grifo nosso).
Além disso, alguns entrevistados ressaltam novamente a questão da concentração do ecossistema carioca em algumas regiões específicas, sinalizando que muitas vezes as redes existentes articulam-se somente em determinadas partes da cidade, formando bolhas difíceis de serem rompidas.

[...] a articulação (recursos financeiros, apoio político, etc.) se faz presente em alguns territórios (Zona Sul, Centro e mais recentemente Barra). Os demais territórios, onde principalmente a Economia Criativa mostra sua face com maior potencial, infelizmente acabam sendo renegados. (Entrevistado 3, 2017).

As redes são ativas e se articulam entre si, mas é muito difícil transbordar da bolha. Não é algo que seja disseminado, do alcance de todos. A não ser quem esteja ativamente envolvido no movimento. A periferia nunca é envolvida (...). (Entrevistada 15, 2017, grifo nosso).

\subsection{CAPITAL FINANCEIRO}

No que diz respeito à dimensão "Capital Financeiro", o representante da PUC-Rio observa que no Rio de Janeiro a figura do investidor anjo ainda é muito pouco desenvolvida, assim como a figura de capitalista de risco (Entrevistado 1, 2017). Na mesma linha, o entrevistado que atua como investidor alerta para a escassez de "funding, tanto público quanto privado" (Entrevistado 6, 2017). Este mesmo entrevistado possui uma visão demasiado cética em relação ao cenário de venture capital da cidade.

É um panorama pouco estimulante. Pouco dinheiro, poucos investidores e pouco incentivo. A von- 
tade de empreender é que é grande. Os desafios são imensos. Muito devido ao baixo montante de recursos disponíveis para esse fim, muito também por baixa capacitação dessas empresas e empreendedores. (Entrevistado 6, 2017, grifo nosso).

No polo oposto, a entrevistada que integra um importante grupo associativo de Capital de Risco na cidade possui uma perspectiva mais otimista da situação.

O panorama do investimento privado no Rio de Janeiro é cada vez mais positivo, com a abertura de novos fundos e fortalecimento de grupos de anjos. (Entrevistada 7, 2017).

Não obstante, a entrevistada sinaliza que o desafio das startups cariocas transcende a questão do acesso a crédito e financiamento, relacionando-se, sobretudo, com a dificuldade de atingir o nível de maturidade necessário para a obtenção de investimento. Em geral, este problema reflete a escassez de aceleradoras de startups na cidade.

O principal desafio das startups cariocas em grande parte não é só o acesso a crédito e financiamento em si, e sim, chegar em um estágio de maturidade que tenha alinhamento com a tese de investimento de anjos e fundos. Cada vez mais vejo um movimento de startups com pouca ou nenhuma tração tentando captar investimento, quando na verdade, deveriam estar focadas na validação do negócio como um todo - o que certamente sinaliza a falta desse elo da aceleradora (...). (Entrevistada 7, 2017, grifo nosso).

\subsection{CULTURA}

Para a maioria dos entrevistados, a cidade do Rio de Janeiro possui uma cultura empreendedora pouco desenvolvida ou praticamente inexistente, caracterizada por aversão ao risco e visão negativa do fracasso. O representante da PUC-Rio sinaliza que mesmo entre os estudantes da universidade - tradicionalmente associada ao empreendedorismo -, o desejo de abrir uma empresa é bastante reduzido.

[...] se o cara tem ali na frente a chance de fazer um concurso público e ser aprovado, ou a oferta de um emprego eminente, e uma terceira opção que é abrir a sua própria empresa, sua própria startup, você me dizer que no Rio de Janeiro o cara pega a opção 3, eu acho que não é real, não é realista. Essa é a minha visão. Ele vai pegar a 1 ou a 2. Talvez, alguns peguem a 3 . O número que eu tenho aqui é o seguinte: cerca de 1 a 3\% vai pegar a opção 3. (Entrevistado 1, 2017, grifo nosso).

O representante da UFRJ, por seu turno, busca justificar essa ausência de cultura empreendedora na cidade por razões históricas:

Aversão ao risco se faz presente em boa parte da geração pré-Plano Real e isso é totalmente compreensível sob o olhar da Economia Comportamental. Somado ao isso temos o fato da cidade ter sido capital do país e um resquício de tudo que existe de ruim no setor público ter ficado com as empresas públicas federais aqui presente ( $20 \%$ da população é de servidor). Ve- 
jam bem, não estou atacando o setor público, contudo as piores práticas foram bem absorvidas na cultura popular em um grau elevado e isso reflete inclusive na tentativa de desestimular aqueles que querem empreender (seja família, amigos, etc.). (Entrevistado 3, 2017).

Na mesma linha, os entrevistados que atuam em uma instituição de suporte do ecossistema reforçam esta percepção, enfatizando que a atual crise contribui para piorar a situação:

No Rio de Janeiro, quase ninguém quer comprar o preço da inovação: criou-se uma cultura em que ninguém arrisca. De forma geral, o risco do fracasso ainda é visto como algo negativo, sobretudo, [em] uma cidade em crise e onde há pouco estímulo para isso. (Entrevistados 14, 2017, grifo nosso).

E o representante de uma plataforma voltada para empreendedores completa:

Eu não acho que existe uma cultura empreendedora no Rio de Janeiro, ainda que existam várias pessoas que tem esse perfil. (Entrevistado 20, 2017).

Além da aversão ao risco e visão negativa do fracasso, alguns entrevistados sinalizam outros problemas na cultura empreendedora do Rio de Janeiro, como excesso de vaidade e falta de colaboração.

[...] acho que existe muita vaidade dentro da cultura empreendedora no Rio, onde a imagem é muito mais valorizada que os fatos, e por muitas vezes essa vaidade acaba prejudicando o nasci- mento de uma cultura mais forte com foco no crescimento e aprendizado real. (Entrevistado 11, 2017, grifo nosso).

Os cariocas primam pelo que é seguro, não entendem que compartilhar casos de fracasso ou aprendizado seja algo de relevância. (Entrevistado 19, 2017).

Por outro lado, uma parte dos entrevistados compartilha uma visão mais positiva acerca da cultura empreendedora da cidade, afirmando que ela existe apesar de ainda não ser tão consolidada como a de outras cidades, e esbarrar em alguns obstáculos, tais como: foco em ideias em detrimento do desenvolvimento de produtos, falta de incentivo por parte de instituições e empreendedores e fragilidade do ambiente de negócios.

A cultura empreendedora no Rio de Janeiro tem uma forte tendência para a área de economia criativa, tecnologia e fintechs, porém é uma cultura fortemente arraigada na criação de ideias, mas com muito pouca conversão em projetos, produtos e empresas. (Entrevistado 2, 2017, grifo nosso).

\section{Existe uma cultura empreendedora no Rio,} mas o Rio não tem as ferramentas para fazer o negócio crescer. Vemos startups que nascem e morrem por falta de incentivo, pouco apoio de instituições e empreendedores que estejam disponíveis para dar mentorias. (Entrevistada 15, 2017, grifo nosso).

O Rio por vocação tem inovação e empreendedorismo na veia, entretanto o inovar/empreender depende de realizar, e o ambiente de negócio do Rio é frágil e burocrático. (Entrevistado 17, 2017). 
A despeito de todas as ressalvas, alguns entrevistados defendem que há uma forte cultura empreendedora na cidade, principalmente ligada a criatividade da população, como observa o entrevistado que presta serviços jurídicos para startups:

A cultura empreendedora está presente no DNA criativo do carioca, somos reconhecidos por apresentar soluções criativas aos desafios apresentados. (Entrevistado 13, 2017, grifo nosso).

\subsection{INSTITUIÇÕES DE SUPORTE}

No que se refere às universidades, os entrevistados apontam que a maioria não estimula o empreendedorismo, e as poucas exceções o fazem ainda timidamente. A PUC-Rio é um ponto fora da curva neste cenário, possuindo forte atuação no estímulo ao empreendedorismo tanto no ensino, quanto na pesquisa e na extensão. Segundo o representante da universidade:

[A PUC-Rio] estimula [o empreendedorismo], mas eu acho que nem todas estimulam. Eu conheço várias universidades que no máximo tem uma disciplina de empreendedorismo, não cultivam essa temática. (Entrevistado 1, 2017, grifo nosso).

De acordo com o representante do Instituto IBMEC, as universidades cariocas estão começando a despertar para a importância do tema.

As universidade começaram a acordar [agora] para a necessidade do tema. O objetivo deve ser a criação de cursos de graduação, pós e exten- sões com metodologias práticas, apoiadas em processos paralelos de incubação e/ou aceleração. (Entrevistado 2, 2017).

O representante da UFRJ, por sua vez, destaca o insulamento das universidades em relação à sociedade e a falta de percepção das mesmas em relação aos benefícios decorrentes do apoio ao empreendedorismo.

[...] devido ao insulamento [perante a sociedade] as universidades pouco estimulam empreendedorismo [...], além de não compreenderem que estimular seria benéfico para elas mesmo. Seja em termos de gerações de soluções internas (via hackathons, por exemplo), endowments, publicidade do nome, etc. (Entrevistado 3, 2017, grifo nosso).

E completa sinalizando que existem iniciativas por parte da universidade, apesar de serem pontuais.

Pelo menos na UFRJ, temos situações pontuais com professores, organizações estudantis e algumas da estrutura da própria Universidade. (Entrevistado 3, 2017).

O representante de uma comunidade de startups da cidade, por seu turno, tem uma visão negativa da atuação das universidades cariocas.

Não vejo as atividades atuais com bons olhos. São esparsas e não estão focadas no resultado coletivo. (Entrevistado 19, 2017).

Em relação às instituições de suporte de forma geral, os entrevistados acreditam que as 
mesmas devem atuar como catalisadores do ecossistema, apoiando ações, articulando iniciativas, estimulando a troca de experiências e incentivando o surgimento de negócios.

As associações têm que passar a se entender como plataformas, e podem ter diferentes papeis de acordo com o seu perfil, algumas mais focadas para troca de experiências, geração de negócios, e outras com um foco voltado para representatividade por exemplo. (Entrevistado 11, 2017).

\section{As instituições de suporte devem atuar} como catalizadores do ecossistema, contribuindo com sua articulação e consolidação. (Entrevistado 13, 2014, grifo nosso).

Os coworkings podem ter um papel bem significativo nesse ecossistema, abrindo os espaços para trocas de experiências e conversas para que as startups possam ter acesso a empreendedores que já estão consolidados no mercado, incentivando [assim] o começo dos negócios. (Entrevistada 15, 2017).

\subsection{POLÍTICAS PÚBLICAS}

O representante da comunidade de startups "Cariocas" possui uma visão bastante crítica ao papel do setor público no ecossistema, defendendo a necessidade de uma transformação em sua atuação.

[O] Setor público atua diretamente contra a criação de negócios inovadores. Algo precisa ser feito. (Entrevistado 19, 2017).
O deputado federal entrevistado argumenta que o poder público precisa estar alinhado às tendências atuais, propondo leis que estimulem a atividade empreendedora e melhorem o ambiente de negócios.

O poder público precisa estar sempre antenado com o que há de mais atual e, essencialmente, introduzir leis e normas mais estimulantes, que combatam a burocracia e que gerem mecanismos facilitadores de acesso ao capital e à atividade empreendedora. (Entrevistado 18, 2017).

Na mesma linha, o representante da Associação Comercial do Rio de Janeiro defende que as políticas públicas são importantes para a dinamização do ecossistema, contudo, precisam estar alinhadas a uma estratégia de desenvolvimento mais ampla.

Acredito que as políticas públicas têm o seu papel [no desenvolvimento do ecossistema], principalmente se estiverem alinhadas com um projeto de cidade, assim como acontecem em outros lugares do Brasil e do mundo. (Entrevistado 11, 2017).

O representante do Sebrae/RJ indica que a instituição possui diferentes frentes de atuação no ecossistema, dentre os quais destacam-se:

Incentivar e promover canais de acesso ao mercado de startups digitais; articular uma rede integrada de empreendedorismo e inovação capaz de melhorar o nível de qualidade das startups; promover a governança das startups em nível de operação e tração (...). (Entrevistado 17, 2017). 
A entrevistada que atua na FIRJAN, por seu turno, ressaltou que o papel da instituição é promover a aproximação entre os diversos atores que compõem o ecossistema.

O papel da FIRJAN é justamente na conexão entre atores de forma a fortalecer o ambiente de inovação no Estado. (Entrevistada 16, 2017).

Finalmente, parte dos entrevistados mencionou o Startup Rio - principal programa estadual de apoio ao empreendedorismo digital -, como uma importante iniciativa do governo na dinamização do ecossistema.

O setor público tem um papel importante no processo também como indutor e financiador de iniciativas como, por exemplo, a FAPERJ fez com o programa Startup Rio. (Entrevistada 16, 2017).

Não obstante, os entrevistados chamaram atenção para a instabilidade do programa em razão da falta de recursos. O representante da PUC-Rio ressaltou também que o programa acabou prejudicando algumas iniciativas que já estavam em curso, reforçando a questão da falta de articulação do ecossistema.

[...] [em relação à] entrada do governo na área de startup; legal, criou o Startup Rio. [Porém], o jeito que estava sendo feito no início estava detonando a iniciativa privada que tinha chegado primeiro e que estava desenvolvendo. [Eu] acho que [acabou] prejudicando as iniciativas que estavam sendo feitas, porque aumentou a concorrência pelos empreendimentos. (Entrevistado 1, 2017, grifo nosso).

\subsection{PROPOSTAS}

Considerando os desafios e obstáculos que o Ecossistema de Empreendedorismo carioca enfrenta, questionamos os entrevistados sobre quais seriam as propostas para tornar este ecossistema mais dinâmico e relevante. Um dos eixos explorados foi a necessidade de se realizar um planejamento que envolva organização, união e metas claras para a consolidação do ecossistema no médio e longo prazos.

[Propostas:] metas claras, entregas claras, grupos de desenvolvimento, liderança ativa e conselheiros. (Entrevistado 2, 2017).

União com extrema organização e planejamento (...), [além da] criação [de] produtos gratuitos para ajudá-los a empreender. (Entrevistado 9, 2017, grifo nosso).

Outro ponto explorado pelos entrevistados refere-se à necessidade do governo agir no sentido de melhorar o ambiente de negócios através da desburocratização, deduções fiscais, simplificação tributária e estímulo a investimentos de impacto.

[...] é necessário aprimorar o ambiente de negócios da região e investir na desburocratização, facilitando e acelerando o processo de abertura e fechamento de empresas. [...] [Também é preciso] simplificar o pagamento de tributos, principalmente para pequenas e médias empresas. (Entrevistados 14, 2017, grifo nosso).

[Deve-se] estimular os investimentos no setor com deduções fiscais. A lei do investidor anjo foi um avanço, mas deveria vir com pacote tri- 
butário junto, aproveitando melhor as perdas e isentando lucros para esse tipo de investimento. (Entrevistado 6, 2017).

Além do planejamento e melhoria do ambiente de negócios, parte dos entrevistados também sinalizou a necessidade de promover uma maior articulação dos atores que compõem o ecossistema e buscar uma maior integração com outros ecossistemas.

[...] deve-se facilitar e melhorar a articulação de todos os atores que compõem o ecossistema de inovação na cidade, aproximando, assim, gestores, empreendedores, investidores, acadêmicos entre outros participantes deste ambiente. (Entrevistados 14, 2017, grifo nosso).

Maior capacidade de comunicação dos achievements das startups locais; [e] mais integração com outros ecossistemas. (Entrevistado 19, 2017).

A grande maioria dos entrevistados enfatizou que a dinamização do ecossistema empreendedor da cidade do Rio de Janeiro depende de dois elementos fundamentais. Em primeiro lugar, os players sugerem a criação de mais espaços compartilhados para empreendedores e startups, facilitando o relacionamento e colaboração entre os atores, e dando visibilidade às conquistas das startups locais.

Acho que se tivéssemos um lugar tipo Google Campus ou o Cubo, onde várias startups estão baseadas, poderíamos acelerar o processo de desenvolvimento desse ecossistema. (Entrevistado 4, 2017).

Algo que seria interessante a criação de um espaço compartilhado para facilitar o rela- cionamento e comunicação dos protagonistas cariocas, o que poderia significar o início de mais parceiras, a fim de construir colaborativamente um ambiente melhor (...). (Entrevistada 7, 2017, grifo nosso).

Incentivo a espaços colaborativos. Imagina um coworking com Wi-Fi público. (Entrevistado 10, 2017, grifo nosso).

É muito importante abrir mais espaço de troca, promover eventos que incentivem o empreendedorismo, hackathons. E encontrar uma forma dessas iniciativas chegarem a todos, de ampliar o público e a rede. (Entrevistada 15, 2017, grifo nosso). [Também] poderiam ser aproveitados prédios ou ambientes subutilizados da cidade para criar espaços de coworking para startups. (Entrevistados 14, 2017).

Por fim, paralelamente, os entrevistados propõem que sejam realizados com mais frequência eventos voltados para empreendedores e startups, com objetivo de promover a troca de experiências, gerar oportunidades, estabelecer redes, e construir uma identidade para o ecossistema carioca.

Criar calendário múltiplo e conectado, eventos, ambiente de networking, mentoria e investimento de forma a manter as startups do Rio no Rio, sem que elas se mudem para outros Estados. (Entrevistado 17, 2017).

Acredito que a promoção de eventos de maior relevância e com mais habitualidade ajudará no diálogo das diversas iniciativas existentes e identificação dos pontos de convergência da comunidade. (Entrevistado 13, 2017, grifo nosso). 
[...] apoio à realização de eventos e feiras periódicos também seria uma forma de criar oportunidades de contato na área. (Entrevistados 14, 2017).

\section{CONSIDERAÇÕES FINAIS}

O objetivo deste trabalho foi o de investigar os desafios, obstáculos e propostas para a conso- lidação de um Ecossistema de Empreendedorismo no Rio de Janeiro, por meio da análise dos principais domínios de um Ecossistema de Empreendedorismo, tanto na revisão bibliográfica - adequada ao contexto atual -, quanto nos dados obtidos das entrevistas realizadas com os diferentes atores do Ecossistema de Empreendedorismo da cidade do Rio de Janeiro. O Quadro 3 traz a síntese dos principais resultados.

Quadro 3: Síntese dos resultados

\begin{tabular}{|c|c|}
\hline Categorias & Resultados \\
\hline \multirow{3}{*}{ Desafios } & Ecossistema pouco desenvolvido; incipiente; imaturo. \\
\hline & Falta de densidade e alto grau de concentração em partes específicas da cidade. \\
\hline & $\begin{array}{l}\text { Ausência de articulação; carência de organização institucional e problemas de } \\
\text { gestão. }\end{array}$ \\
\hline \multirow{2}{*}{ Obstáculos } & $\begin{array}{l}\text { Nível macro (nacional): excesso de burocracia; crise econômica; e questões legais - } \\
\text { trabalhista, tributária, fiscal e regulatória - que influenciam negativamente a atividade } \\
\text { empreendedora. }\end{array}$ \\
\hline & $\begin{array}{l}\text { Nível micro (local): custos elevados da cidade - aluguel, mão de obra e de vida -; } \\
\text { violência urbana; mobilidade urbana ineficiente; infraestrutura precária; e dificuldade } \\
\text { de acesso a capital. }\end{array}$ \\
\hline \multirow{2}{*}{ Articulação } & $\begin{array}{l}\text { Pouca interação entre atores devido à dificuldade de comunicação e diálogo; } \\
\text { desinteresse em cooperar; e falta de engajamento e mobilização. }\end{array}$ \\
\hline & $\begin{array}{l}\text { Redes ativas muito concentradas em determinadas partes da cidade, formando ilhas } \\
\text { desconectadas e bolhas difíceis de romper. }\end{array}$ \\
\hline \multirow{2}{*}{ Capital Financeiro } & $\begin{array}{l}\text { Panorama pouco estimulante: poucos investidores; poucos incentivos e escassez de } \\
\text { capital de risco. }\end{array}$ \\
\hline & $\begin{array}{l}\text { Startups cariocas têm dificuldade de atingir nível de maturidade suficiente para obter } \\
\text { investimento. }\end{array}$ \\
\hline \multirow{3}{*}{ Cultura } & $\begin{array}{l}\text { Cultura empreendedora pouco desenvolvida e/ou quase inexistente: aversão ao risco } \\
\text { e visão do fracasso como algo negativo. }\end{array}$ \\
\hline & Cultura marcada por excesso de vaidade e ausência de colaboração. \\
\hline & $\begin{array}{l}\text { Criatividade do carioca é vista como elemento capaz de desenvolver uma cultura } \\
\text { empreendedora mais robusta na cidade. }\end{array}$ \\
\hline \multirow{2}{*}{ Instituições de Suporte } & $\begin{array}{l}\text { Maioria das universidades não estimula o empreendedorismo: poucas disciplinas } \\
\text { voltadas para o tema e iniciativas isoladas. }\end{array}$ \\
\hline & $\begin{array}{l}\text { Associações devem ser catalisadores do ecossistema, mas ainda estão longe de } \\
\text { exercer este papel. }\end{array}$ \\
\hline
\end{tabular}




\begin{tabular}{|c|l|}
\hline \multirow{4}{*}{ Políticas Públicas } & $\begin{array}{l}\text { Pouco incentivo governamental e legislação que atua contra a atividade } \\
\text { empreendedora. }\end{array}$ \\
\cline { 2 - 3 } & $\begin{array}{l}\text { Iniciativas prejudicadas por falta de recursos e desarticuladas de outras iniciativas } \\
\text { lideradas pelo setor privado. }\end{array}$ \\
\hline \multirow{4}{*}{ Propostas } & Realizar um planejamento que envolva organização, união e metas claras. \\
\cline { 2 - 3 } & $\begin{array}{l}\text { Melhoria do ambiente de negócios através de: desburocratização, deduções fiscais, } \\
\text { simplificação tributária e estímulo a investimentos de impacto. }\end{array}$ \\
\cline { 2 - 3 } & Promover uma maior articulação entre os atores que compõem o ecossistema. \\
\cline { 2 - 3 } & Criação de mais espaços compartilhados para empreendedores e startups. \\
\cline { 2 - 3 } & Realização mais frequente de eventos voltados para o ecossistema. \\
\hline
\end{tabular}

Fonte: Elaboração Própria (2017)

Nota-se que a maioria dos entrevistados concorda que o Ecossistema de Empreendedorismo da cidade do Rio de Janeiro se encontra nos estágios iniciais de desenvolvimento e enfrenta desafios basicamente em três esferas: (i) Pessoal: relacionados à falta de maturidade, ausência de colaboração, bem como disputas de ego; (ii) Organizacional: relacionados à ausência de organização, gestão e planejamento eficazes para o ecossistema; e (iii) Densidade: referentes à localização geográfica, polarização de iniciativas e ausência de conexão e articulação.

Além disso, os resultados obtidos apontam para obstáculos macros, relacionados às questões burocráticas legais, tais como societárias, trabalhistas e fiscais, de abrangência nacional, assim como para obstáculos micros, relacionados à própria dinâmica da cidade do Rio de Janeiro, que carece de segurança pública efetiva, mobilidade urbana adequada, e infraestrutura eficiente, além de contar com um alto custo de instalação física de iniciativas empreendedoras.

Importante destacar a tendência apresentada pela pesquisa que aponta como obstáculos questões relacionadas à burocracia, custos, legislação, infraestrutura da cidade, entre outros, o que, contudo, se refletiu de forma mais tímida nas propostas apresentadas pelos próprios players, que se concentraram, majoritariamente, em planejamento e integração de iniciativas, criação de espaços de inovação e colaboração, além de realização de eventos relevantes ao empreendedorismo. A partir disto, podemos levantar a hipótese de que os obstáculos locais e nacionais, relacionados basicamente à legislação, burocracia, infraestrutura, mobilidade e custos, apesar de relevantes para os empreendedores na condução de seus negócios, podem não ser fatores primordiais para o insucesso do Ecossistema de Empreendedorismo do Rio de Janeiro, o qual carece de maior densidade e integração entre os diversos domínios, além de espaços físicos e eventos voltados para incentivar a cultura e a educação empreendedora como forma de estimular e capacitar os empreendedores do ecossistema.

Os resultados obtidos dos Desafios demonstram uma evidente preocupação dos players com a falta de articulação das "ilhas" de iniciativas da cidade do Rio de Janeiro, que acaba por manter o ecossistema pouco desenvolvido, sem densidade e polarizado geograficamente. É nessa perspectiva que as principais propostas foram fundamentadas, destacando-se a necessidade de 
organização e criação de espaços colaborativos (hubs, coworkings, entre outros) que permitam a integração e o relacionamento entre empreendedores e startups, a formação e ampliação de redes, networking e eventos com conteúdo de relevância, capazes também de melhorar a cultura empreendedora e facilitar trocas, engajamento e futuro acesso ao capital.

A pesquisa, por fim, abre espaço para outras indagações: A baixa articulação das iniciativas interfere na ausência de dimensões como Cultura empreendedora, Capital Financeiro e apoio das Ins- tituições de Suporte, ou a falta de ações positivas destas que dificulta a articulação das iniciativas? A crise política e financeira da cidade do Rio de Janeiro tem influência decisiva no cenário do Ecossistema Empreendedor ou as ações dos players podem por si só superar os desafios e obstáculos apontados? As ações propostas relacionadas à criação de espaços colaborativos, realização de eventos e integração entre startups e empreendedores devem advir da iniciativa privada, Estado ou ambos? Estas são algumas perguntas que podem ser respondidas em futuras pesquisas.

\section{REFERÊNCIAS}

ACS, Z.J.; DESAI, S.; HESSELS, J. Entrepreneurship, economic development and institutions. Small Business Economics, v. 31, n. 3, p. 219234, 2008.

BARDIN, L. Análise de conteúdo. São Paulo: Edições 70, 2011.

CARVALHO, L. M.; VIANA, A. MANTOVANI, D. M. O papel da FAPESP no ecossistema empreendedor do Estado de São Paulo. Revista de Administração, Contabilidade e Economia da FUNDACE (RACEF). Edição: v. 7, Ed. Especial, Ribeirão Preto, março de 2016.

ENDEAVOR BRASIL. Índice de Cidades Empreendedoras - Brasil, 2014. Disponível em: https://rdstation-static. s 3 . a mazonaws. com/cms\% 2 Ffiles \%2F6588\%2F14253228992014-\%C3\%8Dndice_de_Cidades_Empreendedoras-Endeavor.pdf.
ENDEAVOR BRASIL. Índice de Cidades Empreendedoras - Brasil, 2015. Disponível em: https://rdstation-static.s3.amazonaws.com/ cms\%2Ffiles\%2F6588\%2F1449751848Relatorio_Digital_Indice_Cidades_Empreendedoras_ Spread.pdf.

ENDEAVORBRASIL. Índice de CidadesEmpreendedoras - Brasil, 2016. Disponível em: https://d335luupugsy2. cloudfront.net/cms\%2Ffiles\%2F6588\%2F14793793 47ICE+2016+-+Links+V1.pdf

ENDEAVOR BRASIL. Rio de Janeiro Empreendedor: Os pontos fortes e os desafios da Cidade Maravilhosa para se tornar a capital do empreendedorismo, 2014. Disponível em: https://rdstation-static.s3.amazonaws.com/ cms\%2Ffiles\%2F6588\%2F1425322649Rio_ de_Janeiro_Empreendedor_-_2014_-_Endeavor_-_vFinal.pdf. 


\section{REFERÊNCIAS}

FELD, B. Startup Communities: building an entrepreneurial ecosystem in your city. Hoboken: NJ, Wiley, 2012.

FUERLINGER, G.; FANDL, U.; FUNKE, T. The role of the state in the entrepreneurship ecosystem: insights from Germany, Triple Helix, v. 2, n. 3, 2015.

\section{GOMES, L. A. Corrida maluca em territóri-} os desconhecidos: como empreendedores gerenciam incertezas individuais e coletivas em ecossistemas empreendedores. Tese de doutorado apresentada ao Departamento de Engenharia de Produção da Escola Politécnica da Universidade de São Paulo. São Paulo, 2013.

ISENBERG, D. J. The big idea: How to start an entrepreneurial revolution. Harvard Business Review, 2010.

ISENBERG, D. J. The entrepreneurship ecosystem strategy as a new paradigm for economy policy: principles for cultivating entrepreneurship. Babson Entrepreneurship Ecosystem Project, Babson College, Babson Park: MA, 2011.

ISENBERG, D. J. Applying the ecosystem metaphor to entrepreneurship: Uses and abuses. In: AMERICAN ANTITRUST INSTITUTE 2015 Symposium in Washington D.C., Paper [...]. 2015.

KANTIS, H.; FEDERICO, J. Entrepreneurial Ecosystems in Latin America: the role of policies, 2012. Disponível em: http://www.innovacion.gob.cl/ wp-content/uploads/2012/06/Entrepreneurial-Ecosystems-in-Latin-America_the-role-of-policies.pdf.
KELLY, D.; BOSMA, N.; AMOROS, J. E. Global Entrepreneurship Monitor - 2010 Executive Report. [On-line], 2010. Disponível em: http://www. gemconsortium.org.

MASON, C.; BROWN, R. Entrepreneurial ecosystems and growth oriented entrepreneurship. In: OECD LEED Programme and the Dutch Ministry of Economic Affairs on Entrepreneurial Ecosystems and Growth Oriented Entrepreneurship, Paper [...]. The Hague, Netherlands, 2014.

MEHO, L. I. E-mail Interviewing in Qualitative Research: A Methodological Discussion. The Journal of the American Society for Information Science and Technology, v. 57, n. 10, p. 12841295, 2006.

OLIVEIRA, C. A.; COZZI, A. O.; NOGUEIRA, V.; COSTA, V. O Ecossistema Empreendedor brasileiro de Startups: Uma análise dos determinantes do empreendedorismo no Brasil a partir dos pilares da OCDE. Fundação Dom Cabral (FDC): Núcleo de Inovação e Empreendedorismo. Relatório de Pesquisa. Nova Lima, MG: 2013.

ROUNDY, P. T. Start-up Community Narratives: The Discursive Construction of Entrepreneurial Ecosystems. The Journal of Entrepreneurship, v. 25, n. 2, p. 232-248, 2016.

SILVA, A.; FOSSÁ, M. Análise de Conteúdo: Exemplo de Aplicação da Técnica para Análise de Dados Qualitativos. In: Encontro de Ensino e Pesquisa em Administração e Contabilidade, 4., 2015. Anais [...]. Brasília, 2013. 


\section{REFERÊNCIAS}

STAM, E. Entrepreneurial Ecosystems and Regional Policy: A Sympathetic Critique. European Planning Studies, v. 23, n. 9, p. 1759-1769, 2015.

STAM, E.; SPIGEL, B. Entrepreneurial Ecosystems. Utretch University: School of Economics, Discussion Paper Series nr: 16-13, 2016.
STORPER, M. Regional Economies as Relational Assets. In: LEE, Roger; WILLS, Jane (Eds.). Geographies of Economies. Arnold: New York, 1997.

VENKATARAMAN, S. Regional Transformation through Technological Entrepreneurship, Journal of Business Venturing, v. 19, n. 1, 2004, p. 153-167. 